\title{
Skin impression with acetate tape in Demodex canis and Scarcoptes scabiei var. vulpes diagnosis
}

\author{
[Impressão cutânea com fita de acetato no diagnóstico de Demodex canis $e$ \\ Sarcoptes scabiei var. vulpes] \\ D.T. Pereira ${ }^{1}$, L.J.M. Castro $^{3}$, V.B. Centenaro ${ }^{3}$, A.S. Amaral $^{2}$, \\ A. Krause $e^{1,2}$, C. Schmidt ${ }^{2}$ \\ ${ }^{1}$ Aluno de pós-graduação - Universidade Federal de Santa Maria -UFSM- Santa Maria, RS \\ ${ }^{2}$ Universidade Federal de Santa Maria - UFSM - Santa Maria, RS \\ ${ }^{3}$ Aluna de graduação - Universidade Federal de Santa Maria - UFSM - Santa Maria, RS
}

\begin{abstract}
This study compares the efficacy of skin impression with acetate tape and the deep skin scraping test to find $D$. canis and $S$. scabiei in dogs. During six months, 134 samples were collected by both techniques from 115 dogs treated at the dermatology service of the Veterinary Hospital of the Federal University of Santa Maria (HVU-UFSM). Of these patients, 27 had demodicosis and 12 had scabies. The impression with acetate tape test (ITT) was shown to be significantly superior to the deep skin scraping test (DSST) in finding $D$. canis and $S$. scabiei mites $(\mathrm{p}=0.007)$. Based on our results we could conclude that acetate tape impression is a reliable method for diagnosing and monitoring therapy of dermatopathies caused by mites and can be used to replace the traditional deep skin scraping method. In addition, since it is less traumatic for the dog, this method shows more acceptance by the owner.
\end{abstract}

Keywords: dog, acetate tape, demodicosis, scabies

\section{RESUMO}

Este estudo compara a eficácia da impressão cutânea com fita de acetato ao raspado cutâneo profundo para a pesquisa de $\mathrm{D}$. canis $e \mathrm{~S}$. scabiei. Em um período de seis meses, foram coletadas 134 amostras de cada uma das técnicas de um total de 115 cães atendidos na rotina dermatológica do Hospital Veterinário Universitário da Universidade Federal de Santa Maria (HVU-UFSM). Desses pacientes, 27 cães apresentavam sarna demodécica e 12 cães, escabiose. A impressão cutânea com fita de acetato, quando comparada ao raspado cutâneo profundo, demonstrou ser significativamente superior na pesquisa dos ácaros $\mathrm{D}$. canis $e \mathrm{~S}$. scabiei $(p=0,007)$. Conclui-se que o método da fita de acetato pode ser usado em substituição ao raspado profundo de pele para o diagnóstico e controle da terapia das enfermidades dermatológicas produzidas por ácaros. Além de ser um método sensível, ele é menos traumático para o animal, sendo, dessa forma, mais aceito pelo proprietário.

Palavras-chave: cão, fita de acetato, demodicose, escabiose

\section{INTRODUCTION}

Parasitological skin examination is an essential dermatology routine test used as a screening for skin acaridae in order to obtain diagnosis. Although dermatoscopy is the most common method used in human dermatology, deep skin scrapping test (DSST) is the most commonly used test in veterinary medicine, because of its low cost and feasibility, and, although not always being diagnostic, it became indispensable in dermatological practice (Hnilica, 2011a).

The skin of animals is exposed to a variety of parasites, which are able to cause diseases, especially generalized demodicosis and canine scabiosis. Even if the cutaneous alterations in

Recebido em 19 de maio de 2013

Aceito em 25 de junho de 2014

E-mail: desydere@gmail.com 
infection are sometimes mild, the dermatologist should be able to diagnose such affections (Scott et al., 2001).

Canine demodicosis is a severe and highly prevalent parasitic dermopathy caused by a proliferation of Demodex canis mites in hair follicles and sebaceous glands. While destroying the hair follicles, the parasite causes a dermal inflammation which is followed by a secondary infection. The usual agent of these infections is the Staphylococcus pseudointermedius, which causes important skin lesions in the affected dogs (Ravera et al., 2011).

Canine scabiesis is a highly pruritic and transmissible skin disease caused by the proliferation of Sarcoptes scabiei var. vulpes mites (Terada et al., 2010). Pruritus becomes more intense three to six weeks after infection and is present for a long period before a proper treatment is carried out (Currier et al., 2012).

The gold standard to diagnose D. canis is the examination of deep skin scrapping specimens under the microscope, where adult and/or immature forms of the parasite are visualized. Trichoscopic examination which is performed with the hair picked with the root has been proposed as an additional method to search the mites, especially in areas where scrapping is difficult, such as face and feet (Saridomichelakis et al., 2007).

According to Saridomichelakis et al. (2007) the analysis of contaminated skin exudate showed good efficacy in finding Demodex canis, when compared to deep skin scrapping and to the Tricogram. More recently, Pereira et al. (2012) described the use of acetate tape impression method, reporting $100 \%$ efficacy against $90 \%$ of the deep skin scrapping in founding Demodex canis mites.

For searching and diagnosing scabies (S. scabiei var. vulpes) the tape impression method is not used as a standard so far. According to Curti (2004) and Terada et al. (2010) the diagnosis is given when adult or other developing stadium mites are found in the deep skin scrapping specimen. However, since the detection sensitivity is low, diagnosis is often based on the combination of clinical signs and response to therapy.
This work aims to report the efficacy of the tape impression test (ITT) method compared to the gold standard, the DSST, to detect D. canis and $S$. scabiei in naturally infected dogs.

\section{MATERIAL AND METHODS}

In a six month period (April to October, 2012), 115 dogs presenting dermatopathies where treated in the dermatological routine. Of these, $12(10.34 \%)$ dogs were diagnosed with scabiosis, $27(23.47 \%)$ with demodicosis and $78(67.82 \%)$ had no parasitary dermatopathies. In addition, 19 samples were collected as follow-up of animals previously diagnosed with demodicosis which were in treatment. All dogs were scheduled for the dermatologic workflow routine, which includes the following steps: general and specific anamnesis, general clinical examination and complementary exams.

All dogs were submitted to parasitological examination, when both methods (DSST and ITT) were performed on the same lesions, in adjacent sites, in order to allow the comparison between both techniques.

For ITT, a $5 \mathrm{~cm}$ transparent acetate tape (regardless of the supplier) was used. The tape was placed on the lesion site, with the pressure of the thumb and the index fingers, with the purpose of dislodging the mites outwards the follicle to attach them on the tape. After the pressure on the skin surface, the tape was removed and placed on a microscope glass slide (Figure 1). The DSST was performed on the same skin lesion, when a scalpel bladder $\mathrm{nr} 4$ was used until capillary bleeding was observed. The material obtained was placed on a glass slide containing liquid glycerin. The samples were immediately analyzed under the microscope at 100x magnification. The finding of one or more adult organisms of D. canis or S. scabiei was considered positive.

The obtained results from ITT and DSST from animals positive for Demodex sp. (initial samples, follow-up, initial samples + follow up samples) and scabies were compared using the Fisher Exact Test and frequency differences were considered statistically significant when the $\mathrm{p}$ value was $\leq 0.05$. The results of the combined dermatopathies (demodicosis + scabiosis) were analyzed using the $\chi^{2}$ test. 


\section{RESULTS AND DISCUSSION}

In this study, the presence of one or more adult or immature forms of D. canis or S. scabiei was considered as a positive diagnosis in both methods, the DSST and the ITT. Fondati et al. (2009) reported the presence of $D$. canis in only $6 \%$ of samples obtained from healthy animals. Mueller et al. (2012) consider the finding of only one mite a strong suggestion of demodicosis.

Among 27 dogs positive for demodicosis, 25 presented the generalized and two the localized form. Localized demodicosis is defined when the affected animal presents up to four lesions with a diameter below $2.5 \mathrm{~cm}$. The prognosis of the latter is considered better and the lesions can heal spontaneously, while the generalized form is a serious disease which can be fatal in some cases (Mueller et al., 2012).

We could not identify a gender predilection for demodicosis among the 27 positive dogs, $62.9 \%$ (17/27) which were younger than one year, and the age ranged from 2 months to 12 years. This age distribution is similar to that reported by Saridomichelakis et al. (2007), who found a mean age of 10 months and a range of 2.5 months to 12 years.

The majority of dogs had a defined breed (59.3\%) (4 shih tzu, 3 pugs and 2 yorkshire terriers). Other affected breeds were the English bulldog, boxer, chow chow, great dane, miniature pinscher, border collie and beagle. These results are in accordance to previously reported information (Scott et al., 2001; Pereira et al., 2012), and confirm the hereditary compound in the susceptibility to develop demodicosis.

At the presentation the skin examination comprised both DSST and ITT, which were performed in areas presenting lesions and on the same site. Demodex sp. was detected in $27 \mathrm{dogs}$ with the ITT and in 22 dogs using the DSST, representing a $18.51 \%$ false-negative rate (Table 1). Statistical analysis showed a marked superiority of ITT compared to DSST in detecting Demodex organisms ( $p=0.05)$.

Table 1. Comparison of demodicosis and scabiosis positive and negative diagnostic frequencies using the impression tape test (ITT) and the deep skin scrapping test (DSST)

\begin{tabular}{|c|c|c|c|c|c|}
\hline Sample & & $\begin{array}{c}\text { Positive } \\
\mathrm{n}(\%)\end{array}$ & $\begin{array}{c}\text { Negative } \\
\mathrm{n}(\%)\end{array}$ & Total & $P$ \\
\hline \multicolumn{6}{|l|}{ DEMODICOSIS } \\
\hline \multirow{3}{*}{ Initial diagnosis } & & & & & $0.05^{*}$ \\
\hline & ITT & $27(100 \%)$ & $0(0 \%)$ & 27 & \\
\hline & DSST & $22(81.5 \%)$ & $5(18.5 \%)$ & 27 & \\
\hline \multirow[t]{3}{*}{ Follow-up } & & & & & $0.194 *$ \\
\hline & ITT & $12(63.1 \%)$ & $7(36.9 \%)$ & 19 & \\
\hline & DSST & $7(36.9 \%)$ & $12(63.1 \%)$ & 19 & \\
\hline \multirow[t]{3}{*}{ Diagnosis + follow-up } & & & & & $0.031 *$ \\
\hline & ITT & $39(84.8 \%)$ & $7(15.2 \%)$ & 46 & \\
\hline & DSST & $29(63.1 \%)$ & $17(39.9 \%)$ & 46 & \\
\hline \multirow[t]{3}{*}{ SCABIOSIS } & & & & & $0.037 *$ \\
\hline & ITT & $5(41.7 \%)$ & $7(58.3 \%)$ & 12 & \\
\hline & DSST & $0(0 \%)$ & $12(100 \%)$ & 12 & \\
\hline \multirow[t]{3}{*}{ DEMODICOSIS + SCABIOSIS } & & & & & $0.007 * *$ \\
\hline & ITT & $44(75.9 \%)$ & $14(24.1 \%)$ & 58 & \\
\hline & DSST & $29(50 \%)$ & $29(50 \%)$ & 58 & \\
\hline
\end{tabular}

${ }^{*}$ Fisher Test; ${ }^{* *} \chi^{2}$ Test.

As demodicosis is a disease which requires a follow-up with serial parasitological examinations until the patient can be considered cured, 19 follow-up samples were collected during the time of analysis. Of these, 12 were positive in the ITT, whereas only 7 were positive using the DSST. All patients with both ITT and DSST negative were considered cured (Table 1).

Regarding the total samples positive for Demodex (initial diagnosis + follow-up), statistical analysis showed a difference $(p=0.031)$ 
in positivity for demodicosis, when comparing positivity frequency between tape impression test and deep skin scrapping for demodex positive animals (Table 1), showing that the ITT is superior compared to the DSST, including patient follow-up.

In this study we obtained $100 \%$ de sensitivity in positive samples for $D$. canis which were collected with acetate tape against $81.5 \%$ (Tab. 1) of samples obtained with the DSST for initial diagnosis demodicosis. These results agree with Pereira et al. (2012), which reported 100\% positivity in acetate tape samples in animals with democidosis, reinforcing the view that this is a very suitable technique to diagnose this disease. Mueller and colleagues (2012) presented different results and recommended the use of ITT only as an alternative for the DSST when the parasitary load is abundant. In our study we observed positive results in animals presenting high and low parasite numbers using the ITT.

We were able to visualize all development stages of $D$. canis in slides prepared with the ITT samples and a higher number of mites could be observed on the same microscopic field in comparison to the DSST. Another important aspect to be mentioned is the absence of blood and minor amount of crust and cell debris in ITT samples, facilitating the parasite count and improving the diagnostic efficiency. (Figure 2).

According to Scott and colleagues (2001), the diagnosis of scabiosis is usually less precise, since approximately $80 \%$ of skin tests can be negative even in positive animals. This is the reason why clinicians base their diagnosis mostly on anamnesis data, especially when an intense pruritus with sudden onset is referred and on the response to therapy (Terada et al., 2010). However, this conduct can erroneously lead to a scabies diagnosis, because therapy would eliminate other mite species improving the clinical condition (Curti, 2004).

Because of its high mobility and slower proliferation, the detection of Sarcoptes scabiei in skin tests is usually difficult, leading to the need of more reliable sampling methods.
In a 6 month period we treated 12 animals which were suspected of having scabiosis. All were younger than 12 months. Prevalent breeds were chow-chow and shih-tzu (3 of each), yorkshire terier, great dane and bull terrier (one of each) and three were mixed-breed dogs. There was no gender predilection. According to Hnilica (2011b), scabiosis is a highly contagious disease, and is common in dogs living in shelters, households with many animals, pet shops and dog show pets. In our study the animals were either recently acquired from pet shops or adopted from shelters or rescued from the street.

Collected samples from skin affected areas from these animals were positive in 5 animals using ITT $(41.7 \%)$ (Figure 3 ), and all were negative for DSST. There was a significant difference between both tests in detecting Sarcoptes mites $p$ $=0.037$ (Tab. 1). These results show that ITT can be used as a good alternative to DSST because it is less traumatic and more efficient for $S$. scabiei detection.

S. scabiei is a highly moving mite, which burrows under the host's epidermis, making a positive sampling from the skin difficult. The lesions are pruritic and erythema, excoriation. Hair loss and crusts are commonly seen secondary alterations (Scott et al, 2001).

In seven dogs, none of the sampling methods resulted in positive tests. In those cases, presumptive diagnosis was obtained based on the clinical signs and on the response to therapy. All animals presented intense pruritus, positive pinnal-pedal scratch reflex and lesions at the border of the ears, elbow and abdomen. Some animals had disseminated lesions. Mueller and colleagues (2001) reported that $82 \%$ of animals with scabies were positive for the pinnal-pedal reflex. According to Hnilica (2011a) scabies can be diagnosed by the observation of the clinical signs, which include intense pruritus, and skin lesions which can vary from papules, erythema, excoriations, alopecia and crusts, localized in most cases in poorly haired regions, such as hock, elbow, pinna and ventral chest and abdomen. 

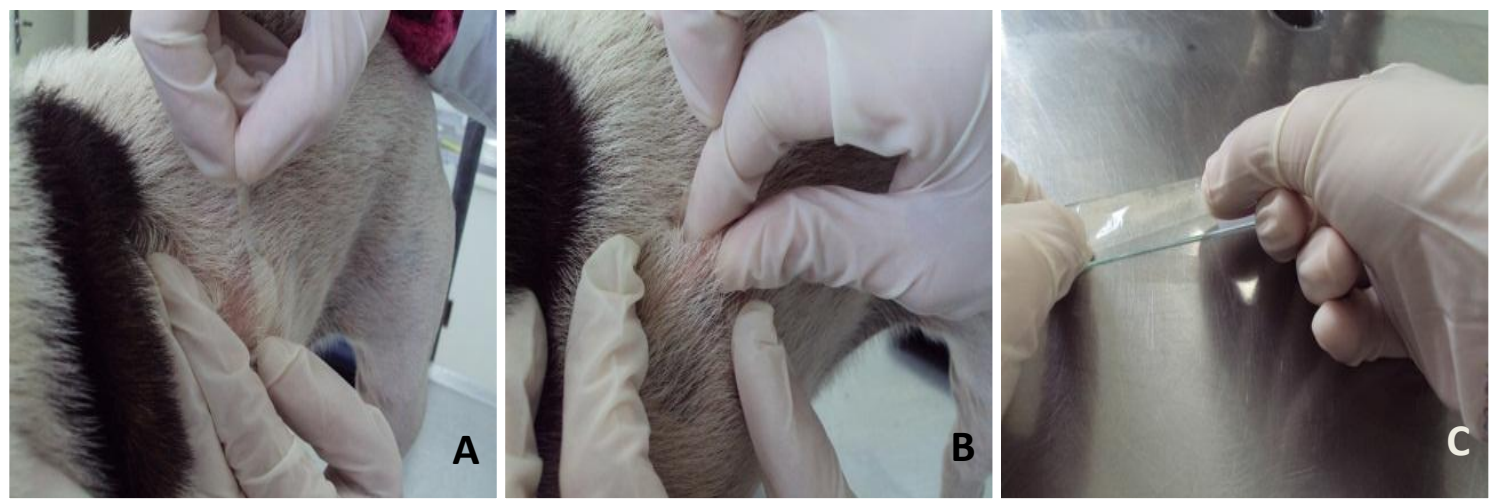

Figure 1. Acetate tape skin impression technique: (A) The acetate tape is placed on the selected lesion site; (B) skin submitted to pressure under the tape (C) tape placed on a glass slide.


Figure 2. Microscopic view of ITT (A) and DSST (B) samples obtained from the same dog with demodicosis. The higher number of mites in A can be noted, as well as the presence of blood in B. Magnification 200x.

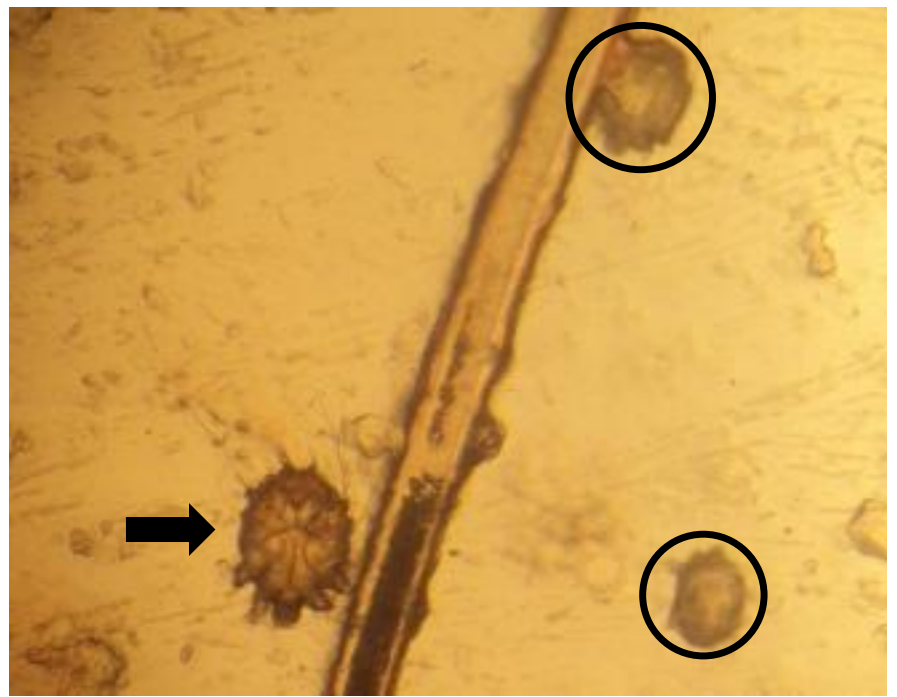

Figure 3. Adult (arrow) and immature (circle) forms of $S$. scabiei vizualized under the microscope from samples obtained from a bull terrier using impression of the skin with an acetate tape. Magnification 400x. 
In order to statistically evaluate the efficacy of the ITT as a sampling method to diagnose demodicosis and scabiosis, we compared the efficiency of finding mites in 58 demodicosis or scabies dogs. Using ITT, we could identify mites in 44 samples, (75.86\%), against $29(50 \%)$ positivity using the traditional DSST (Tab. 1).

In addition, none of the 78 samples collected from dog diagnosed for other non parasitary dermopathies was positive for mites using the ITT, demonstrating a high specificity, which enable us to indicate this test as a screening for skin parasites in the routine dermatology.

\section{CONCLUSION}

This study could demonstrate that the parasitological examination using the acetate tape sampling is an efficient method to identify D. canis and S. scabiei and was statistically superior as the deep skin scrapping test. The ITT was suitable to screen for D. canis at the initial diagnosis and at the follow-up until the end of treatment of canine demodicosis. Regarding scabiosis, $41.7 \%(5 / 12)$ of all dogs could be diagnosed by observation of the mites under the microscope in ITT, whereas no mite could be found with the DSST. Based on this result we suggest the use of ITT in screening for scabiosis. The ITT is an easy, safe and sensitive test which can be adopted for parasitological screening in veterinary dermatology routine.

\section{REFERENCES}

CURRIER, R.W.; WALTON, S.F.; CURRIE, B.J. Scabies in animals and humans: history, evolutionary perspectives, and modern clinical management. Ann. N.Y. Acad. Sci., v.1230, p.E50-E60, 2012.

CURTI, C.F. Current trends in the treatment of Sarcoptes, Cheyletiella and Otodectes mite infestations in dogs and cats. Vet. Dermatol., v.15, p.108-114, 2004.
FONDATI, A.; DE LUCIA, M.; FURIANI, N. et al. Prevalence of Demodex canis-positive healthy dogs at trichoscopic examination. Vet. Dermatol., v.21, p.146151,2009

HNILICA, K.A. Diagnostic techniques. In: HNILICA, K.A. Small animal dermatology: a color atlas and therapeutic guide. 3. ed., St. Louis: Saunders Elsevier, 2011a. p.22-36.

HNILICA, K.A. Parasitic skin disorders. In: HNILICA, K.A. Small animal dermatology: a color atlas and therapeutic guide. 3. ed., St. Louis: Saunders Elsevier, 2011b. p.120-158.

MUELLER, R.S.; BENSIGNOR, E.; FERRER, L. et al. Treatment of demodicosis in dogs: 2011 clinical practice guidelines. Vet. Dermatol., v.23, p.86-e21, 2012.

MUELLER, R.S.; BETTENAY, S.V.; SHIPSTONE, M. Value of the pinnal-pedal reflex in the diagnosis of canine scabies. Vet. Rec., v.148, p.621-623, 2001.

PEREIRA, A.V.; PEREIRA, S.A.; GREMIÃO, I.D. et al. Comparison of acetate tape impression with squeezing versus skin scraping for the diagnosis of canine demodicosis. Austr. Vet. J., v.90, p.448-450, 2012

RAVERA, I.; ALTET, L. FRANCINO, O. et al. Development of a real-time PCR to detect Demodex canis DNA in different tissue samples. Parasitol. Res., v.108, p.305-308, 2011.

SARIDOMICHELAKIS, M.N.; KOUTINAS, A.F.; FARMAKI, R. et al. Relative sensitivity of hair pluckings and exudate microscopy for the diagnosis of canine demodicosis. J. compilation, ESVD ACVD, v.18, p.138-141, 2007.

SCOTT, D.W.; MILLER, JR.W.H.; GRIFFIN, C.E. Parasitic skin disease. In: SCOTT, D.W.; MILLER, JR.W.H.; GRIFFIN, C.E. Small animal dermatology. 6. ed. Philadelphia: Elsevier, 2001. p.423-516.

TERADA, Y.; MURAYAMA, N; IKEMURA, H. et al. Sarcoptes scabiei var. canis refractory to ivermectin treatment in two dogs. Vet. Dermatol., v.21, p.608-612, 2010. 